\title{
Restriction endonuclease digestion and chromosome banding in the mosquito, Culiseta longiareolata (Diptera: Culicidae)
}

\author{
Annalisa Marchi and \\ Roberto Mezzanotte
}

Istituto di Biologia Generale, Università di Cagliari, Via Ospedale 119, 09124 Cagliari, Sardinia, Italy.

Fixed chromosomes of the mosquito, Culiseta longiareolata $(2 n=6)$ were treated in situ with nine restriction endonucleases and stained with ethidium bromide or Giemsa. All the heterochromatic regions were apparently protected from digestion by all enzymes except Mbo I. This enzyme selectively digested one of the three types of heterochromatin present in the species. Staining with the fluorochrome quinacrine after enzyme treatment produced a standard $Q$-banding pattern or a Hoechst 33258-like pattern, depending on the enzyme. These results confirmed: (a) the presence of three types of heterochromatic containing different DNA fractions in the chromosomes of this species, (b) restriction enzymes accessibility to the DNA of heterochromatin regions, and (c) the selective cleavage of particular DNA fractions without DNA removal. Moreover, quinacrine staining after enzyme digestion proved useful in detecting differential activity among enzymes which produced the same banding pattern with standard dyes.

\section{INTRODUCTION}

In situ digestion with restriction endonucleases (RE), which cleave DNA at specific target sequences, has been shown to produce consistent banding patterns in fixed mammalian and insect chromosomes. Correspondence between several RE banding patterns and the localisation by in situ hybridisation of particular DNA fractions (satellite DNAs and amplified genes) has been ascertained in man, mouse and Drosophila species (Miller et al., 1983; Kaelbling et al., 1984; Mezzanotte, 1986; Mezzanotte et al., 1986). Extraction of cleaved DNA fragments from fixed chromatin has been proposed as the predominant mechanism producing chromosome banding after RE treatment (Miller et al., 1983; Bianchi et al., 1985). However, RE bandings are not always associated with DNA extraction. On this base, conformational changes of the chromosome structure caused by the nicking of DNA molecules, rather than DNA loss, have been suggested to explain the results produced by some REs in human chromosomes (Mezzanotte et al., 1985). Difficult access of the enzyme to the chromosomal DNA has also been considered as possible cause of the observed patterns. The relative importance and interrelationship of these factors in inducing longitudinal differentiation in fixed chromosomes are still not clearly understood. Nevertheless, the combined use of different restriction endonucleases proved useful in the detection of different classes of chromatin not revealed by standard banding techniques.

The chromosome complement of Culiseta longiareolata (Macquart), a common palaearctic mosquito, has been analysed using standard banding techniques and, more recently, Alu I digestion (Mezzanotte et al., 1979a,b,c; Mezzanotte and Ferrucci, 1983). On these grounds, three types of heterochromatin were identified and the presence of different classes of DNA was indicated. We tested the action of nine restriction endonucleases, already used on mammals and other Diptera, in order (a) to further characterise and discriminate between the different types of chromatin present in this species, and (b) to gain additional information on restriction enzyme activity in fixed chromosomes.

\section{MATERIALS AND METHODS}

Larvae of Culiseta longiareolata were collected from several localities in southern Sardinia. Cephalic ganglia and gonads were dissected from 
fourth instars, fixed in methanol: acetic acid $(3: 1)$ and squashed in 45 per cent acetic acid under a siliconised coverslip. Slides were then placed on dry ice and the coverslip removed. Restriction enzyme treatment was carried out according to Mezzanotte et al. (1983). Alu I, Mbo I, Hha I, Hae III, Hpa II, Msp I, Dde I, Hinf I and Bam HI were purchased from Boehringer (FRG) and New England Labs. (U.S.A.). Cytological preparations, aged 2-7 days at $4^{\circ} \mathrm{C}$, were incubated at $37^{\circ} \mathrm{C}$ for $16 \mathrm{hrs}$ in $100 \mu \mathrm{l}$ of the enzyme solution (10-20 units of one enzyme in a Tris-saline buffer (Maniatis et al., 1982)). The enzyme solution was evenly dispersed on the preparations by use of a coverslip. The treatment was carried out in a moist chamber. Enzyme incubation was stopped by washing the slides in $0.5 \mathrm{M}$ EDTA at $4^{\circ} \mathrm{C}$. Chromosomes were stained with either 5 per cent Giemsa in deionized water or the DNA specific fluorochrome ethidium bromide $\left(0.04\right.$ per cent in $7 \mathrm{mM} \mathrm{Na}{ }_{2} \mathrm{HPO}_{4}, 2 \mathrm{mM}$ $\mathrm{NaH}_{2} \mathrm{PO}_{4}, 180 \mathrm{mM} \mathrm{NaCl}$ and $1 \mathrm{mM} \mathrm{Na}{ }_{2}$ EDTA). The chromosomes were observed with a Dialux
$20 \mathrm{~EB}$ microscope equipped with a $50 \mathrm{~W}$ mercury lamp. Slides treated with Alu I, Mbo, Hae III, Hpa II and Msp I were subsequently destained for at least 30 minutes in ethanol:acetic acid $(3: 1)$ and stained with 0.5 per cent quinacrine dihydrochloride in Sörensen's buffer. Control slides were treated with the incubation buffer without restriction enzyme. A few preparations were processed for C-banding. Both control and C-banded slides were destained as described above and stained with quinacrine.

\section{RESULTS}

The longitudinal differentiation produced in the chromosomes of $C$. longiareolata by eight of the nine restriction enzymes tested was similar to the C-banding pattern obtained by alkaline treatment (figs 1,2,3). After digestion with one of the following enzymes, Alu I, Hha I, Hae III, Hpa II, Msp I, Dde I, Hinf I, Bam HI, and staining with
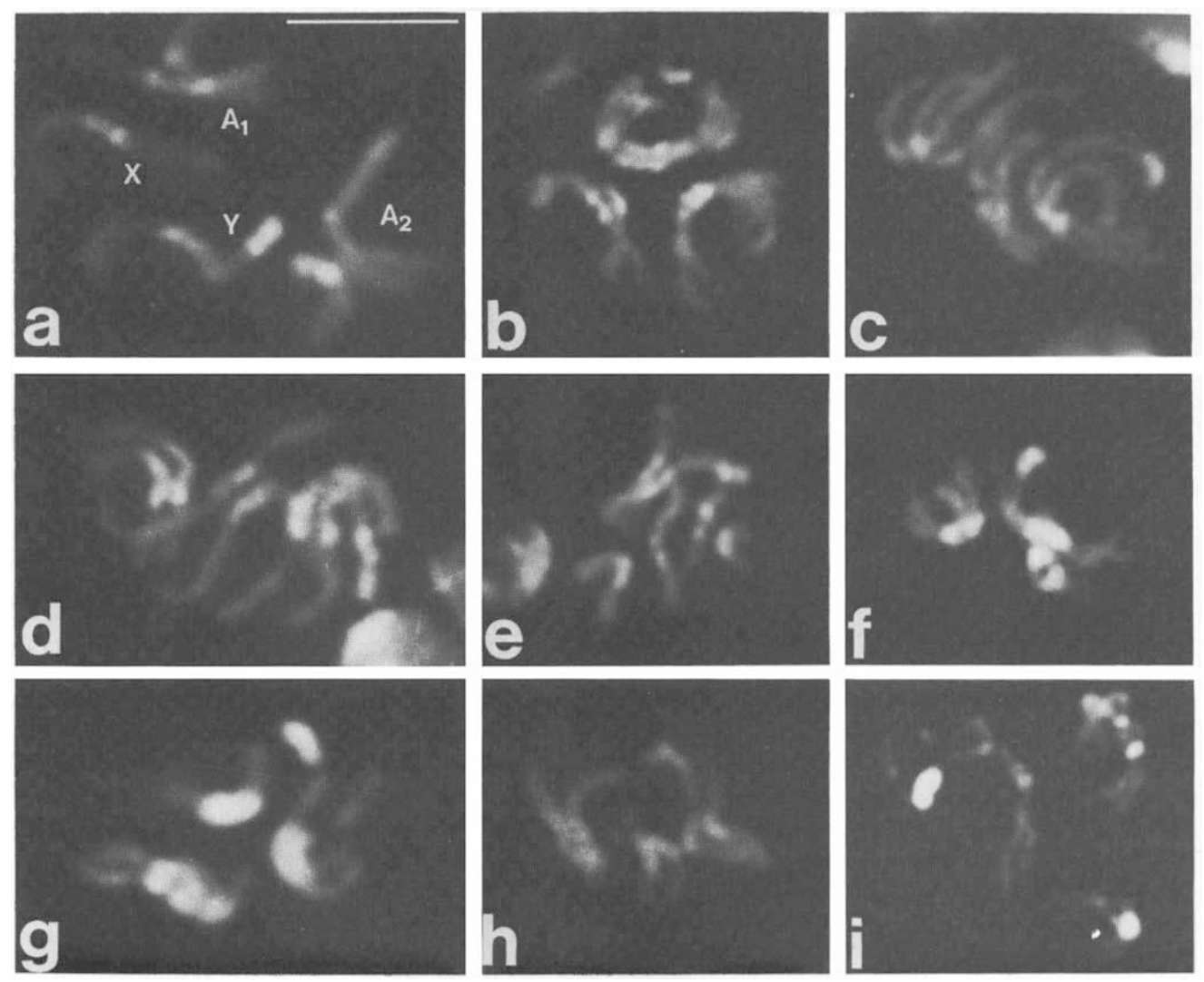

Figure 1 Banding patterns of $C$. longiareolata chromosomes after enzyme digestion and staining with ethidium bromide: (a) Alu I; (b) Hha I; (c) Hae III; (d) Hpa II; (e) Msp I; (f) Dde I; (g) Hinf I; (h) Bam HI; (i) Mbo I. Bar=10 $\mu \mathrm{m}$ in all figures. 
ethidium bromide (EB), the heterochromatic, $\mathrm{C}^{+}$, pericentromeric regions of the three chromosome pairs and the heterochromatic telomere of the Y chromosome showed an intense bright fluorescence (fig. 1). The chromosome arms fluoresced dully. Intercalary bands of intermediate fluorescence were observed along the arms, but their appearance was not constant in all metaphases. An analogous banding pattern was obtained when enzyme treatment was followed by Giemsa staining (figs. 2, 3).

Selective digestion of some $\mathrm{C}^{+}$heterochromatic regions was characteristic of Mbo I treatment (figs. $1 \mathrm{i}, 3 \mathrm{e}$ ). The paracentromeric heterochromatin on the short arm of the sex chromosomes and on the long arm of the shortest chromosome pair $\left(A_{1}\right)$ appeared weakly stained with both EB and Giemsa. The other $\mathrm{C}^{+}$centromeric regions and the heterochromatic telomere of the $\mathrm{Y}$ chromosome showed bright fluorescence with EB and dark staining with Giemsa. The chromosome arms were weakly stained. However, additional bands were consistently present on the arms of the three chromosome pairs. A few minor bands were detected with Giemsa but not with EB staining.

In control preparations the staining reaction with EB and Giemsa was intense and uniform all over the chromosomes.

Quinacrine staining after treatment with Alu I, Mbo I, Hae III, Hpa II and Msp I produced different results, depending on the enzyme. A standard Q-banding pattern (fig. 2b) was observed after digestion with Alu I and Hae III (figs. 2d, f). However, the fluorescence intensity of some minor, faint Q-bands within the telomeric heterochromatin of the $\mathrm{Y}$ chromosome appeared sometimes

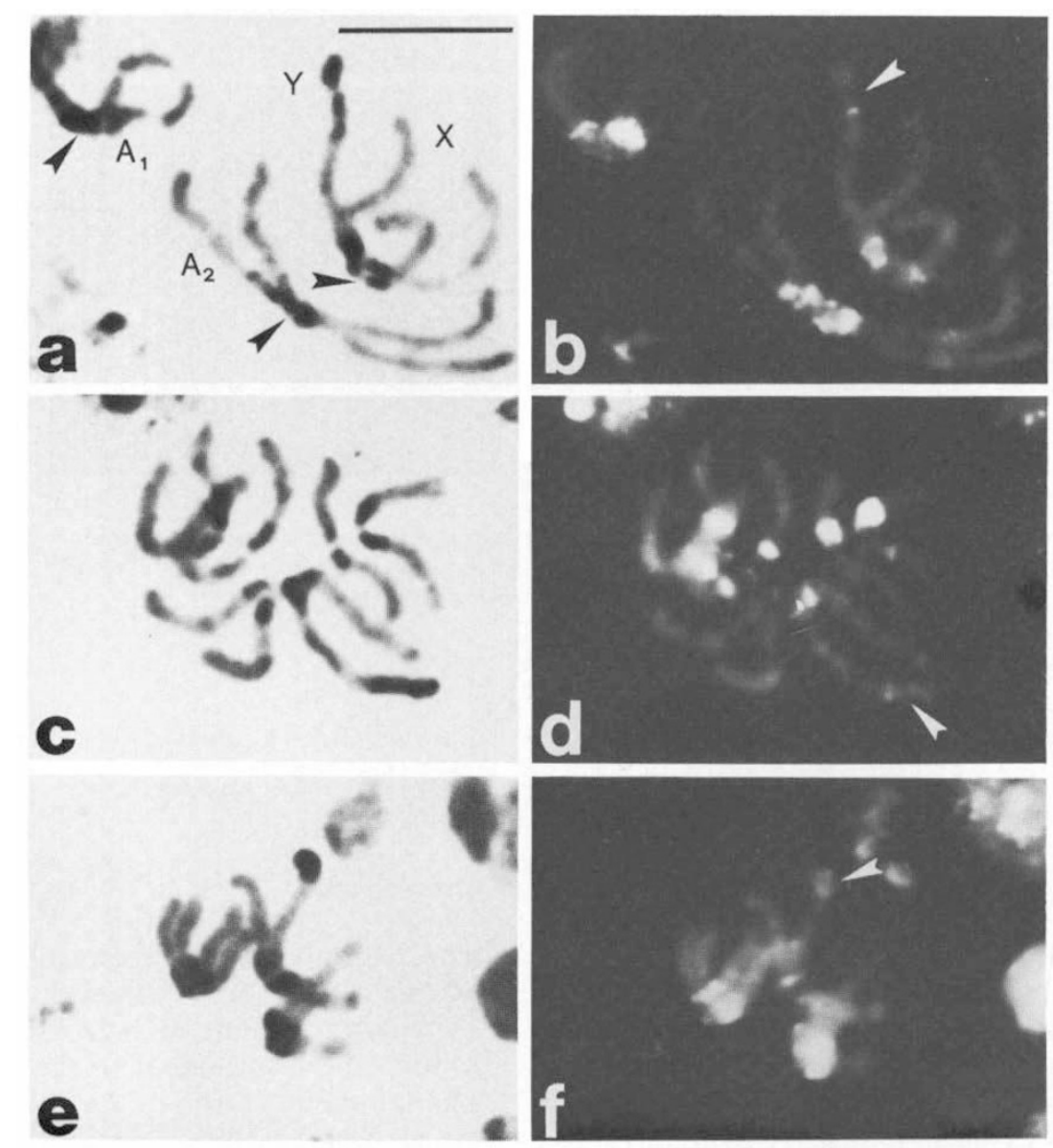

Figure 2 Metaphase chromosomes of C. longiareolata after digestion with Alu I (c) and Hae III (e) (Giemsa staining). The same metaphases were destained and treated with quinacrine dihydrochloride (d)-(f). A C-banded (a) and Q-banded (b) metaphase is shown for comparison. Black arrows point to the centromeres, white arrows to the telomere of the $\mathrm{Y}$ chromosome. 


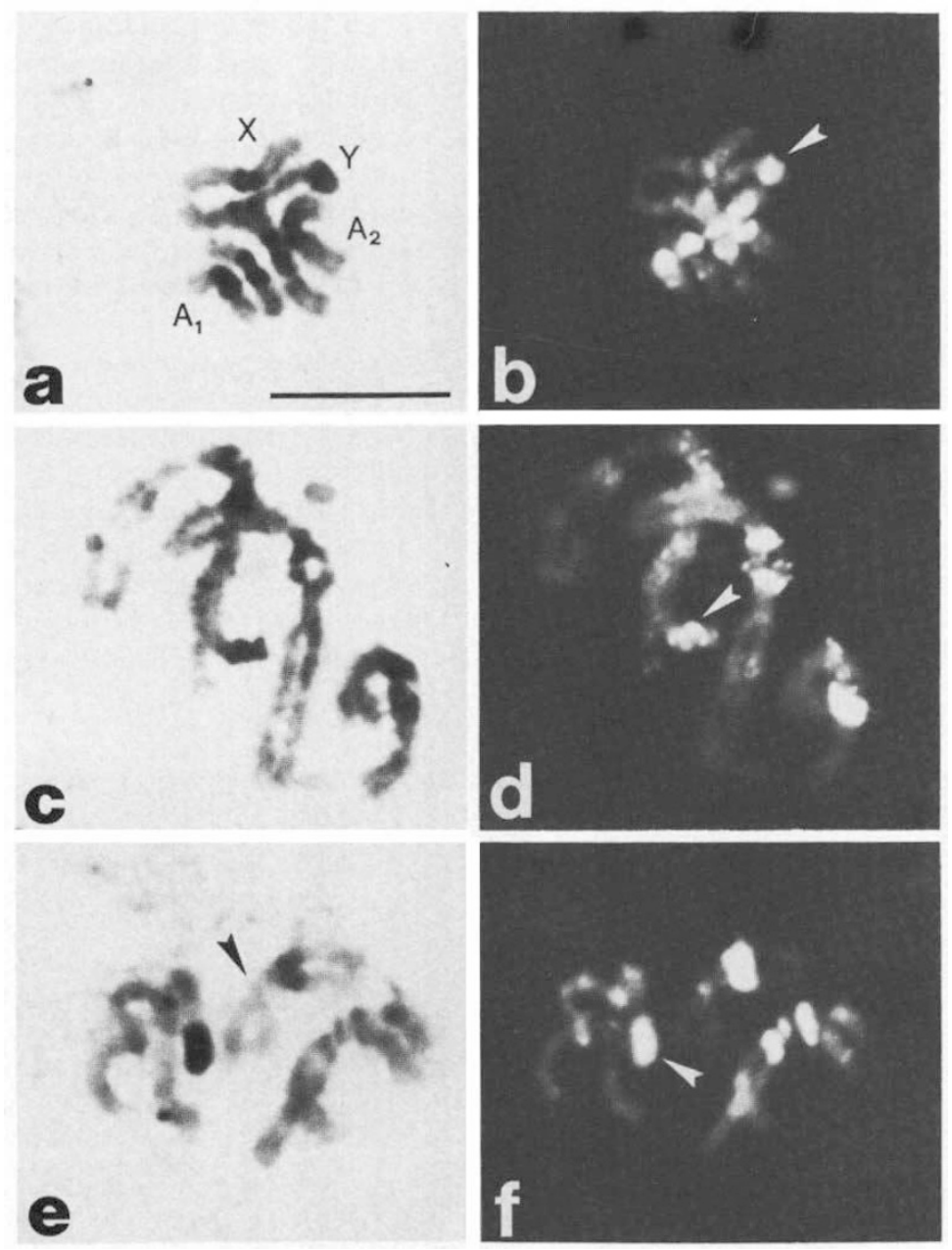

Figure 3 Metaphase chromosomes of $C$. longiareolata after enzyme digestion and subsequent staining with quinacrine dihydrochloride: Hpa II (a)-(b); Msp I (c)-(d), Mbo I (e)-(f). The black arrow points to the heterochromatic region of chromosome $\mathrm{A}_{1}$ digested by Mbo I. White arrows point to the bright fluorescing $\mathrm{Y}$ telomere.

slightly enhanced. The banding pattern produced by quinacrine staining after treatment with $\mathrm{Hpa}$ II, Msp I and Mbo I differed from the standard Q-banding pattern in the preserice of very bright fluorescence on the heterochromatic $Y$ telomere (figs. 3b, d, f). The fluorescence of this region appeared uniformly bright in fully condensed metaphases. However, in earlier mitotic stages three-four bright blocks were clearly seen, while the very tip of the telomere fluoresced dully (fig. $3 d$ ). This pattern was similar to the one obtained after staining with Hoechst 33258 (H-banding) and after Actynomicin-D/acridine orange treatment (Mezzanotte et al., 1979b; Mezzanotte and Ferrucci, 1983). Metaphases from control and C- banded slides showed the standard Q-banding pattern (fig. 2b).

\section{DISCUSSION}

The chromosome complement of Culiseta longiareolata $(2 n=6)$ is characterised by the presence of a large amount of heterochromatin localised around the centromeres of the three pairs and in one telomeric region of the $\mathrm{Y}$ chromosome. Two types of heterochromatic $\left(\mathrm{C}^{+} \mathrm{Q}^{+} \mathrm{H}^{+}\right.$and $\mathrm{C}^{+} \mathrm{Q}^{-} \mathrm{H}^{-}$ respectively) have been identified in the pericentromeric regions by standard banding techniques and light-induced banding (Mezzanotte et al., 
1979a, b, c). The presence of a different type of heterochromatin $\left(\mathrm{C}^{+} \mathrm{Q}^{-} \mathrm{H}^{+}\right)$has been demonstrated in the telomere of the $\mathrm{Y}$ chromosome by the same techniques.

All the restriction enzymes tested, with the exception of Mbo I, were unable to digest any of the three types of heterochromatin, producing a $\mathrm{C}$-like banding pattern in the chromosomes of $C$. longiareolata. These enzymes cleaved and possibly removed DNA from the euchromatic regions, as suggested by the decreased fluorescence of the chromosome arms after staining with the DNA specific fluorochrome ethidium bromide. On the other hand, the bright fluorescence observed in the heterochromatic regions was interpreted in terms of absence or scarcity of the enzyme target sequences (table 1), and lack of DNA extraction. Correlation between frequency of RE target sequences, DNA extraction and chromatin staining intensity has been suggested by several authors to explain the results obtained in mammals and Drosophila (Miller et al., 1983; Kaelbling et al., 1984; Bianchi et al., 1985; Mezzanotte, 1986). These results indicated that only restriction enzymes which cut isolated DNA in small fragments (100-350 base pairs) produced longitudinal differentiation of chromosomes with extensive DNA loss, while REs which cleave DNA fragments of about 1000 base pairs or more did not cause any appreciable removal of DNA from fixed chromosomes. Long fragments would be less easily removed than short ones because more tightly bound to the chromosomal proteins (Kaelbling et al., 1984). Difficult accessibility of the enzymes to heterochromatic DNA could also have produced the banding patterns observed in $C$. longiareolata, however enzyme access to the DNA of heterochromatic regions was revealed by treatment with Mbo I. This enzyme (target sequence GATC) selectively digested one type of pericentromeric heterochromatic $\left(\mathrm{C}^{+} \mathrm{Q}^{-} \mathrm{H}^{-}\right)$localised on the short arm of the sex chromosomes and on the long arm of the shortest pair.

Additional information on the selective activity of the enzymes was inferred from the results obtained after enzyme digestion and staining with quinacrine. The telomeric heterochromatin of the $\mathrm{Y}$ chromosome was mostly dull fluorescent after Alu I and Hae III treatment (standard Q-banding pattern) but showed bright quinacrine fluorescence after digestion with Msp I, Hpa II and Mbo I (H-like pattern). The DNA of this region is believed to be AT-rich with periodic interspersion of $\mathrm{GC}$ base pairs which quench quinacrine but not Hoechst 33258 fluorescence (Mezzanotte et al.,
$1979 b, c)$. The results obtained after digestion with Hpa II, Msp I and Mbo I suggested the presence of CCGG and GATC target sites in this region and a moderate level of DNA cleavage. The DNA fragments produced by the enzymes would be too long to be removed but sufficient to alter the chromatin structure and to prevent quenching of quinacrine fluorescence by $\mathrm{CG}$ interspersion. In summary, these observations indicated differential restriction activity among enzymes (Alu I, Hae III, Hpa II and Msp I) which produced the same banding pattern with standard dyes. Moreover, they confirmed (a) enzymes accessibility to the DNA of heterochromatic regions, apparently protected from digestion (bright EB fluorescence), and (b) the selective cleavage of particular DNA fractions without DNA removal. Finally, they supported previous observations on the structure of the $\mathrm{Y}$ telomere, implying the presence of $\mathrm{CG}$ sites within AT-rich DNA.

Only a few enzymes have been tested on other Dipteran species. In Drosophila melanogaster and D. virilis good correspondence was found between the banding patterns produced by Alu I and Hae III and the localisation by in situ hydridisation of the main satellite DNAs isolated in these species (Mezzanotte, 1986; Mezzanotte et al., 1986). In another mosquito, Aedes albopictus, Hpa, II, Msp, Hha I and Mbo I have been shown to extract roughly the same amount of DNA (20-30 per cent) from fixed chromosomes (Bianchi et al., 1986). However, Hha I and Msp I did not produce in this species any banding pattern, while centromeric bands were observed after Hpa II and Mbo I digestion. Hpa II and Msp I are isochizomeric and cleave DNA at the same target sequence, CCGG. Their activity is inhibited by methylation of the internal or external cytosine respectively (Maniatis et al., 1982) (table 1). Methylation of the internal cytosine has been suggested to explain the different

Table 1 Restriction endonucleases tested on fixed chromosomes of Culiseta longiareolata and respective cleavage sites. Inhibition by methylation is marked by an asterisk

\begin{tabular}{|c|c|}
\hline Enzyme & Sequence \\
\hline Alu I & $\mathrm{AG} \downarrow^{*} \mathrm{CT}$ \\
\hline Mbo I & $\downarrow G^{*}$ ATC \\
\hline Hha I & $\mathrm{G}^{*} \mathrm{CG} \downarrow^{*} \mathrm{C}$ \\
\hline Hae III & $\mathrm{GG} \downarrow^{*} \mathrm{CG}$ \\
\hline Нра II & $\mathrm{C} \downarrow^{*} \mathrm{CGG}$ \\
\hline Msp I & ${ }^{*} \mathrm{C} \downarrow \mathrm{CGG}$ \\
\hline Dde I & $C \downarrow$ TNAG \\
\hline Hinf I & G\ANTC \\
\hline Bam HI & $\mathrm{G} \downarrow \mathrm{GAT}{ }^{*} \mathrm{CC}$ \\
\hline
\end{tabular}


results obtained in $A$. albopictus after treatment with the two enzymes. In C. longiareolata Hpa II and Msp I produced the same banding pattern, indicating the absence of methylation in their target sequences. Moreover, most of the enzymes we tested are inhibited by methylation of a cytosine or adenine present in their targets (table 1). They all produced extensive cleavage and extraction of DNA from the chromosomes of $C$. longiareolata, suggesting little DNA methylation in this species. This observation agrees with the low methylation level found in purified mosquito DNA (Adams et al., 1979).

Acknowledgements The authors thank L. E. Munstermann for helpful comments on the manuscript.

\section{REFERENCES}

ADAMS, R. L. P., MCKAY, E. L., CRAIG, L. M. AND BURDON, R. H. 1979. Methylation of mosquito DNA, Biochim. Biophis. Acta, 563, 72-81.

BIANCHI, M. S., BIANCHI, N. O., PANTELIAS, G. E. AND WOLFF, S. 1985. The mechanism and pattern of banding induced by restriction endonucleases in human chromosomes. Chromosoma, 91, 131-136.

BIANCHI, N. O., VIDAL-RIOJA, L. AND CLEAVER, J. E. 1986. Direct visualization of DNA methylation in human and mosquito chromosomes. Chromosoma, 94, 362-366.

KAELBLING, M., MILLER D. A. AND MILLER, O. J. 1984. Restriction enzyme banding of mouse metaphase chromosomes. Chromosoma, 90, 128-132.
MANIATIS, T., FRITSCH, E. F. AND SAMBROOK, J. 1982. Restriction enzymes. In Molecular cloning, Cold Spring Harbor, New York, pp. 98-106.

MEZZANOTTE, R. 1986. The selective digestion of polytene and mitotic chromosomes of Drosophila melanogaster by the Alu I and Hae III restriction endonucleases. Chromosoma, 93, 249-255.

MEZZANOTTE, R., FERRUCCI, L. AND CONTINI, C. 1979a. Identification of sex chromosomes and characterization of the heterochromatin in Culiseta longiareolata (Macquart, 1838). Genetica, 50, 135-139.

MEZZANOTTE, R., MARCHI, A. AND FERRUCCI, L. 1979 b. The different banding pattern produced by Hoechst 33258 and quinacrine dihydrochloride in metaphase chromosomes of Culiseta longiareolata (Diptera: Culicidae). Caryologia, 32, 373-377.

MEZZANOTTE, R., FERRUCCI, L. AND MARCHI, A. 1979 c. Lightinduced banding (LIB) in metaphase chromosomes of Culiseta longiareolata (Diptera: Culicidae). Genetica, 51, 149-152.

MEZZANOTTE, R. AND FERRUCCI, L, 1983. The metaphase banding pattern produced in the chromosomes of Culiseta longiareolata (Diptera: Culicidae) by Alu I restriction endonuclease or Actinomycin-D treatment followed by acridine orange staining. Genetica, 62, 47-50.

MEZZANOTTE, R., FERRUCCI, L., VANNI, R., AND SUMNER, A. T. 1985. Some factors affecting the action of restriction endonucleases on human metaphase chromosomes. Exp. Cell Res., 161, 247-253.

MEZZANOTTE, R., MANCONI, P. E. AND FERRUCCI, L. 1986. On the possibility of localizing in situ Mus musculus and Drosophila virilis satelite DNAs by Alu I and Eco RI restriction endonucleases. Genetica, 70, 107-111.

MILLER, D. A., CHOI, Y.C. AND MILLER, O. J. 1983. Chromsome localization of highly repetitive human DNA's and amplified ribosomal DNA with restriction enzymes. Science, 219, 395-397. 